\title{
Antifilosofia: Jean Epstein e realismo especulativo
}

\section{Julio Bezerra}

Doutor; Universidade Federal de Mato Grosso do Sul; Campo

Grande, MS, Brasil

juliocarlosbezerra@hotmail.com

\section{Resumo}

Este artigo tem como objetivo propor um diálogo entre o cinema e a teoria de Jean Epstein e o realismo especulativo. A interação de forças subjetivas e objetivas no cinema é um campo atraente de investigação para um realista especulativo, e a convicção epsteiniana de que o cinema nos abre para novos domínios do conhecimento do mundo está absolutamente sintonizada com esse movimento filosófico. Ao longo desse diálogo, esboçamos um modo diverso de pensar sobre o cinema: uma "antifilosofia".

\section{Palavras-chave}

Jean Epstein. Realismo especulativo. Antifilosofia. Teoria dos cineastas. A. N. Whitehead.

\section{Introdução}

Nascido em Varsóvia, Polônia, em março de 1897 (menos de dois anos após a primeira exibição pública de cinema em Paris ${ }^{1}$ ), Jean Epstein foi cinéfilo, poeta, escritor, cineasta e filósofo do cinema. Ele se envolveu com a sétima arte em um momento de grande emoção e descoberta - um período em que suas possibilidades pareciam ilimitadas e suas implicações ainda a serem pensadas. Em muitos aspectos, apesar das extraordinárias realizações do cinema francês antes e depois da Segunda Guerra Mundial, evidentes nas obras de Marcel L'Herbier, Germaine Dulac, Abel Gance, Fernand Léger, René Clair, Louis Delluc, Jean Renoir e outros (todos tocados em diferentes graus e por períodos variáveis pela influência impressionista), pode-se afirmar que o verdadeiro centro do movimento está

\footnotetext{
${ }^{1}$ Epstein chegou a conhecer Louis e Auguste Lumière em Lyon, quando ainda estudava para ser médico (1917-1920). Sabe-se que os irmãos Lumière o incentivaram a lançar uma revista sobre arte, Le Promenoir.
} 
em seu discurso teórico e nas primeiras tentativas autoconscientes de definir a natureza do cinema (e, portanto, sua diferença em relação às outras artes).

Epstein ficou fascinado pelas relações entre o aparato mecânico e os objetos particulares que ele registra. Não este ou aquele objeto individual, mas todas as coisas que juntas formam um mundo. O que o fascinava era justamente uma, segundo ele, incomparável capacidade cinematográfica de transmitir a verdade da vida em sua glória ilógica, não teleológica, ilimitada e infinitamente mutante. Em Bonjour cinema, Epstein enaltece o cinema como "[uma] nova poesia e filosofia" (EPSTEIN, 1981, p. 9, tradução nossa), uma arte cuja verdade difere da história porque despreza a convenção, considera a encenação absurda e a eloquência morta (EPSTEIN, 1981). Em vez de seguir o drama da ação, a verdade do cinema será encontrada na tragédia suspensa:

A verdadeira tragédia permanece em suspenso. Ameaça todos os rostos. Está na cortina da janela e na maçaneta da porta. Cada gota de tinta pode fazê-la florescer na ponta da caneta-tinteiro. No copo de água, ela se dissolve. Toda a sala está saturada com todo tipo de drama. A fumaça do charuto está ameaçadoramente sobre a garganta do cinzeiro. A poeira é traiçoeira. 0 tapete emite arabescos venenosos e os braços da cadeira tremem. (EPSTEIN, 1981, p. 11, tradução nossa).

Essa suspensão da tragédia foi possível pela não interferência do ser humano na captura dessa realidade. Como diz Jacques Rancière: o filme, para Epstein, era "uma arte" em que a inteligência humana "[...] está sujeita a outra inteligência, a inteligência da máquina que nada quer, que não constrói nenhuma história, mas simplesmente registra a infinidade de movimentos que dá origem a um drama cem vezes mais intenso que todas as dramáticas reviravoltas da fortuna." (RANCIÈRE, 2013, p. 7). Para Epstein, o cinema é mais do que uma forma de entretenimento, um meio de massa, uma nova linguagem visual ou até mesmo uma nova forma de arte. 0 cinema oferece um cérebro mecânico, um olho-máquina - um portal para um novo mundo transformado pela tecnologia: um modo de a percepção humana penetrar na própria vida da matéria.

Essa intenção primordial de nos fazer experimentar os limites de nossa percepção, a incompletude de nossos conceitos e a existência, ainda que fugidia, de um mundo para além de nossa percepção e conceitos humanos está na base do que chamamos de realismo especulativo, uma corrente recente que vem renovando o pensamento filosófico em um processo de revalorização da metafísica, da ontologia e da estética. Este artigo se desenvolve 
em um diálogo entre os escritos e os filmes de Jean Epstein e o realismo especulativo. Ambos parecem desafiar-nos a repensar o mundo dos objetos e das coisas e a relação do homem com esse mundo. A complexa interação de forças subjetivas e objetivas no cinema é um campo atraente de investigação para um realista especulativo, e a conviçcão de que o cinema nos abriria para novos domínios do conhecimento do mundo está absolutamente sintonizada com o ponto-chave desse movimento filosófico: o fato de que o mundo em si - o mundo como existe à parte de nós - não pode, de forma alguma, ser contido ou restringido pela questão do nosso acesso a ele. 0 que se esboça ao fim é a possibilidade uma forma diversa de pensar sobre o cinema: uma "antifilosofia".

\section{Jean Epstein}

Jean Epstein talvez seja o primeiro grande filósofo do cinema. Para ele, a sétima arte não é meramente um aparato ou um meio, nem apenas uma forma de arte ou uma indústria de massa, mas um objeto e evento que muda o mundo, um novo agente, uma nova fonte material para a filosofia - que não poderia dar-se ao luxo de desconsiderar esse fenômeno. Sua obra (seus filmes e livros) é baseada em um conceito, a photogénie, que é da ordem do inefável, quase de uma espécie de mágica. Foi Louis Delluc quem propôs o termo para designar a qualidade única da imagem cinematográfica: "Poucos entenderam o interesse da fotogenia. Além disso, nem sequer sabem o que é." (DELLUC, 1985, p. 34, tradução nossa). A photogénie foi, a princípio, uma noção da fotografia. 0 corpo fotogênico é aquele cuja aparência tem a natureza de dar uma bela cor à fotografia. No cinema, no entanto, a photogénie tornou-se uma relação misteriosa entre a fotografia em geral e certos seres que se prestam a ela. A photogénie não significava belas garotas loiras ou paisagens deslumbrantes, mas uma espécie de intensidade efêmera, que, uma vez notada, só podia ser sustentada por alguns segundos antes de desaparecer.

Epstein afirma, no entanto, que esse momento fugaz, mas concentrado, pode ser capturado pela fotografia. Ele usa o termo photogénie várias vezes em seu trabalho. Sua definição canônica vem de De quelques conditions de la photogénie, de 1924, ensaio coletado em Le cinématographe vu de l'Etna: "Vou denominar fotogênico qualquer aspecto das coisas, seres e almas que realce sua qualidade moral através da reprodução cinematográfica." (EPSTEIN, 1988c, p. 314, tradução nossa). A photogénie é, portanto, o “cinematográfico" per 
se, que não é desvalorizado como uma cópia ou simulacro menos essencial do que o seu modelo, mas, ao contrário, valorizado como o aprimoramento da "qualidade moral" do modelo.

O que se vislumbra quando se trata de fotogenia é seu caráter de valor estético, essencial, mas indescritível; é sentido, mas não explicado; é constitutivo, mas não analisável; "Nós nos matamos querendo defini-lo." (EPSTEIN, 1974, p. 91, tradução nossa). Ao mesmo tempo, essa substância misteriosa é, na verdade, a substância do cinema. 0 termo era fascinante porque era vago e aberto. Epstein foi fiel a ele sem se esforçar muito para explicálo. Em sua discussão sobre a photogénie, Epstein não apenas expressa a dificuldade de definir um conceito que se refere a coisas para as quais não há palavras, mas também sugere que a photogénie é elusiva:

Photogénie não é simplesmente uma palavra elegantemente desvalorizada. Um novo fermento; dividendo, divisor e quociente. Batemos contra a parede tentando defini-la. 0 rosto da beleza é o gosto das coisas. [...] Indescritível, muitas vezes é pisoteada como a promessa de riquezas com as quais uma camada de carvão ainda não descoberta bifurca a terra. (EPSTEIN, 1988a, p. 243-244, tradução nossa).

Quando Epstein retorna ao termo dez anos mais tarde, por volta de 1934-1935, ele acrescenta que apenas "aspectos móveis" são fotogênicos e que, além disso, "apenas aspectos móveis e pessoais das coisas, seres e almas podem ser fotogênicos". (EPSTEIN, 1988c, p. 315, tradução nossa). Associada ao movimento, a photogénie é efêmera; "Photogénie é uma mobilidade no espaço e no tempo. Podemos, portanto, dizer que o aspecto fotogênico de um objeto é uma consequência de suas variações no espaço-tempo." (EPSTEIN, 1988c, p. 316, tradução nossa). Como tal, a photogénie pode ser caracterizada como oferecendo um argumento de especificidade do meio cinematográfico. No entanto, com o risco de aparente contradição, Epstein parece situar a qualidade única do cinema menos em sua diferença para com as outras artes do que em alcançar uma síntese e realização especificamente modernas tanto das artes quanto das ciências, proporcionando novas formas de conhecimento que conjugam a estética e a epistemologia. Como síntese, o cinema não combina simplesmente as várias artes, mas as coloca em um novo patamar, definindo-as não como um modo de representar o mundo, mas como um caminho para penetrá-lo, descobrindo um universo para além da experiência humana: o domínio da 
matéria, do que é dado à consciência, revelando, sobretudo, as leis do tempo entre as camadas mais profundas do movimento e da matéria.

Ao apresentar o mundo em sua mobilidade contínua, o cinema é uma forma peculiar de conhecimento e, por implicar todos os sentidos, tem a capacidade virtuosa de superar nossas limitações fisiológicas. No final de sua vida, Epstein vê o cinema como uma "máquina inteligente" e, mais importantemente, como uma "máquina animista": "Desenvolvendo o alcance de nossos sentidos e jogando com a perspectiva temporal, o cinematógrafo torna perceptível pela visão e pela audição indivíduos que consideramos invisíveis e inaudíveis, revelando a realidade de certas abstrações." (EPSTEIN, 1993, p. 190, tradução nossa). A sétima arte equipara, portanto, um mundo onde é possível combinar ou desconectar espaços e tempos que a visão linear da história sempre nos ensinou a ver em uma suposta unidade inseparável: um espaço-tempo.

Epstein, no entanto, aponta persistentemente para a capacidade sintética do cinema de pausar ou parar o tempo, de congelá-lo em um momento de presença, tornando-o palpável e latente dentro da imagem como uma entidade sensual disponível ao olhar de inspeção do espectador. Na passagem seguinte, Epstein valoriza o close-up precisamente por interromper o fluxo do tempo, mantendo-o em suspenso como pura potência:

Ainda mais bonito do que rir é o rosto se preparando para o riso. Eu devo me intrometer. Adoro a boca que está prestes a falar e se retém, o gesto que hesita entre a direita e a esquerda, o recuo antes do salto e o momento antes de aterrissar, o devir, a hesitação, a mola tensa, o prelúdio e ainda mais do que tudo isso, o piano sendo sintonizado antes da abertura (EPSTEIN, 1988a, p. 236, tradução nossa).

Aqui, o tempo é algo que se torna diretamente visível para o espectador, algo que podemos ver inteiramente congelado na imagem na forma latente de um "recuo", de uma "hesitação" ou de um "devir". E o resultado dessa latência sensual do tempo, para Epstein, é a produção de um momento de presença gestante que pontua e interrompe o fluxo de tempo padrão, contínuo e linear. Durante esses momentos de presença, a organização linear do tempo nas dimensões discretas do passado, presente e futuro é substituída por um momento fecundo, grávido do tempo em que passado e futuro colapsam ou coalescem no presente. 
Do privilégio concedido ao movimento, a photogénie evolui quando se considera a noção de movimento por si só, abstratamente. 0 que é movimento, se não a junção do tempo e do espaço? O cinema tem seus próprios procedimentos temporais, distintos dos procedimentos usuais; o movimento lento e o efeito de aceleração são os modos mais visíveis e mais óbvios de "modelar" o tempo, embora existam muitas outras formas, algumas, inclusive, ainda a serem devidamente experimentadas. Em outras palavras, para Epstein a sétima arte é um pensamento que opera segundo uma nova definição de tempo, inimaginável antes dele. Consequentemente, o cinema produz uma interrogação fundamental do tempo, cuja essência está no seguinte: o cinema não reproduz o tempo, mas produz o tempo.

Em suas últimas reflexões, influenciadas por sua formação científica e seu conhecimento das revoluções da Física no início do século XX, Epstein inverte as prioridades: não é o tempo que deve ser pensado em termos espaciais, mas o contrário. 0 cinema - esse criador de mundos imaginários indefinidos, ilimitados, que podem ser revelados nos filmes - é, consequentemente, uma máquina de pensamento com suas próprias leis, diferente de nosso pensamento; no mundo do cinema, o tempo, o espaço e a causalidade - as principais categorias kantianas - funcionam de maneira bastante diferente da nossa realidade. Para Epstein, o cinema é nada menos que uma máquina filosófica, capaz de nos fazer entender de uma nova maneira as principais categorias do universo.

Em suma: Epstein não estava apenas entre os poucos na era do cinema mudo a considerar o cinema como um objeto de pensamento - uma posição ousada naqueles dias -, mas defendia a visão mais radical de que a sétima arte alterava a experiência, o pensamento e a filosofia, gerando um modo original e não humano de refletir sobre o universo. A convicção de que o cinema se abriria para novos domínios do conhecimento do mundo, indo além dos limites da consciência humana, indica muito mais do que apenas a previsão utópica e esquecida que as primeiras décadas do cinema alimentaram sobre este novo meio. Para Epstein, o cinema está sempre nos forçando a reconhecer os limites das percepções e conceitos humanos e a afirmar a existência de um mundo para além deles. Somos forçados, em suma, a tentar pensar o mundo sem nós. 


\section{Realismo especulativo}

"Sem nós" pode significar tanto "na nossa ausência" quanto "para além de nós". Essa ideia caracteriza o propósito do chamado realismo especulativo, uma tendência recente da filosofia contemporânea caracterizada por sua oposição ao que Quentin Meillassoux nomeou como "correlacionismo": a ideia de que "[...] o pensamento não pode sair de si mesmo para comparar o mundo como ele é 'em si mesmo' e o mundo como ele é 'para nós' e, assim, distinguir o que é uma função de nossa relação com o mundo e o que pertence apenas ao mundo." (MEILLASSOUX, 2008, p. 3, tradução nossa). Os filósofos do realismo especulativo afirmam a existência de uma realidade independente de qualquer acesso humano, e rejeitam a tese kantiana de que o sentido do mundo depende do modo como nossas mentes (ou nossas línguas, ou nossas culturas) trabalham para estruturá-lo. Ao longo desse caminho, eles nos desafiam a pensar o mundo à parte de nossa visão estreita sobre ele, reconhecendo as dificuldades de pensar o impensado (o fora do pensamento, ou o "absoluto", segundo Meillassoux) e sublinhando a importância de especular sobre ele.

Esta curiosa e influente corrente filosófica tem seu momento específico de nascimento quando, em 2007, quatro filósofos apresentaram trabalhos na Universidade de Goldsmiths em Londres sob a bandeira do que eles mesmos chamaram de realismo especulativo. Meillassoux, Graham Harman, Ray Brassier e Iain Hamilton Grant foram percebidos, por vezes, como um grupo relativamente homogêneo, embora alimentem diferenças tão grandes que não se pode dizer que encerrem uma única escola ou movimento filosófico ${ }^{2}$. Suas obras, contudo, compartilham um mesmo ponto de partida: a ideia de que o primado da epistemologia sobre a ontologia que dominou a filosofia desde Kant a aprisionou no exame perpétuo das condições do pensamento.

Enquanto a filosofia contemporânea, em suas mais variadas correntes, tem afirmado que a realidade é algo "construído" pela linguagem, pelo poder ou pelas práticas culturais humanas, o realismo especulativo se configura como uma filosofia mais realista. Isso significa, entre outras coisas, que essa corrente afirma que o mundo externo existe independentemente da consciência humana. Por mais brando e sensato que esse ponto possa soar, ele rompe com a essência do século passado da filosofia continental e nos leva a direções surpreendentemente estranhas ao senso comum.

\footnotetext{
2 Dos quatro integrantes iniciais do realismo especulativo, apenas Harman ainda se sente confortável com a expressão e a defende e dissemina.
} 
A filosofia ocidental moderna - pelo menos desde que Immanuel Kant publicou sua Crítica da razão pura em 1781 - tendeu a privilegiar a epistemologia sobre a ontologia. A ontologia está preocupada com a natureza do ser, com a definição, no nível mais básico, do que é. Epistemologia, em contraste, está relacionada com a forma como sabemos o que é que conhecemos. Ela examina os fundamentos e limites de nossa capacidade de conhecer o mundo. Dizer que a epistemologia deve vir antes da ontologia é simplesmente salientar que, para fazer afirmações sobre como o mundo é, devemos ser capazes de fundamentar essas afirmações, para explicar como podemos saber que elas são verdadeiras.

Em princípio, essa prioridade da epistemologia sobre a ontologia pode parecer inquestionável. Mas, na prática, essa asserção mostrou-se bastante problemática. Isso significa que acabamos falando não sobre as coisas do mundo que encontramos, mas sobre nosso próprio processo de encontrá-las. Kant insiste que "as coisas em si" são incognoscíveis; tudo de que podemos realmente ter certeza são os fenômenos - como as coisas nos parecem. Essa compreensão kantiana se tornou uma espécie de senso comum. Hoje, tomamos como certo que nunca podemos ver as coisas como elas realmente são, porque nunca podemos escapar das lentes distorcidas de nossas próprias imposições ao mundo. Hoje, essas imposições foram além das categorias de Kant para incluir coisas como linguagem, nossos mecanismos cognitivos específicos e nossos preconceitos e ideologias culturais.

Não deixa de ser irônico. Essa reflexão torna quase impossível escaparmos desses preconceitos e suposições. Estamos presos dentro de nossas próprias perspectivas, incapazes de ter uma visão de qualquer outro lugar. É de fato importante e necessário que nos preocupemos com o perigo de nos sobrepormos a tudo - às outras pessoas, às outras entidades vivas e às outras coisas no universo -, de sobrepormos a tudo a nossa própria imagem. Mas pagamos um preço para evitar esse perigo: acabamos nos referindo apenas a nós mesmos. Para a filosofia pós-moderna do final do século $\mathrm{XX}$, de pensadores como Richard Rorty e Jacques Derrida, não há como fugir dessa armadilha: tudo o que podemos fazer é apontar e deplorar isso. Nós nunca podemos ir além de nós mesmos, de modo a encontrar algo genuinamente diferente.

O renascimento da especulação filosófica no século XXI é um esforço para se libertar desse dilema. Ela procura desfazer o privilégio kantiano da epistemologia e evitar tanto o logocentrismo como o etnocentrismo, por um lado, e a desconstrução e autocrítica infinitas, por outro. Kant denunciava a especulação por ultrapassar os limites de todo o conhecimento 
possível. Para os novos pensadores especulativos de hoje, em contraste, a especulação é necessária precisamente por causa dos limites do conhecimento. Há muita coisa que é real, mas que nunca poderemos conhecer. A realidade é muito mais estranha do que podemos imaginar. As coisas nunca estão de acordo com as ideias que temos sobre elas; há sempre algo para além do que somos capazes de entender. É por isso que a especulação é necessária. Devemos especular, fugir do nosso antropocentrismo inveterado e levar a sério a existência de um mundo fundamentalmente estrangeiro, não humano.

Epstein não está tão longe disso. Em seus escritos, ele está a todo o momento jogando com a polissemia de temos como sensível e objetivo, sublinhando que os dois atributos-chave do cérebro-máquina do cinema são sua nova sensibilidade e sua objetividade pós-humana. $\mathrm{O}$ automatismo cinematográfico ataca a discussão entre arte e técnica alterando o próprio status do "real". 0 cinema não reproduz as coisas como elas se oferecem ao nosso olhar; registra-as como o olho humano não pode vê-las, à medida que elas surgem, em um estado de ondas e vibrações, antes que possam ser qualificadas, devido às suas propriedades descritivas e narrativas, como objetos, pessoas ou eventos inteligíveis. Epstein sugere, portanto, que o cinema desenvolve sua própria fenomenologia do mundo e do humano. Uma fenomenologia diversa, como salienta Christophe Wall-Romana, que destitui o hipotético observador sujeito-desencarnado do humanismo: "Em termos fenomenológicos, Epstein argumenta que o cinema oferece um epokhê não humano, um novo modo de suspensão de nossa visão habitual do mundo, uma prótese transcendental de intencionalidade." (WALL-ROMANA, 2017, p. 97, tradução nossa).

Epstein, como os realistas especulativos, rejeita a ideia de que a ordem do mundo depende do modo como nós o estruturamos. Em seus filmes, o cineasta francês descreve um mundo povoado não por sujeitos ativos e objetos passivos, mas por materiais vivos e essencialmente interativos, por corpos humanos e não humanos. Epstein explora a especificidade cinematográfica, investiga noções diversas de tempo e usa o cinema para dar perspectiva ao não humano - aos mais variados espaços, oceanos, marés e tempestades. 0 cinema começa onde o nosso conhecimento sólido termina, convidando-nos a um outro nível de realidade. 0 cinema é uma forma de especulação. É uma viagem ao desconhecido, sem garantias. Para Epstein, um filme pode ir a qualquer lugar e imprimir poderes mágicos às coisas: 
Eu chegaria a dizer que o cinema é politeísta e teogônico. Aquelas vidas que ele cria, evocando objetos das sombras da indiferença para a luz da preocupação dramática, têm pouco em comum com a vida humana. Essas vidas são como a vida em encantos e amuletos, os objetos ameaçadores e tabus de certas religiões primitivas. Se quisermos entender como um animal, uma planta ou uma pedra podem inspirar respeito, medo ou horror, esses três sentimentos mais sagrados, acho que devemos observálos na tela, vivendo suas vidas misteriosas e silenciosas, estranhas à sensibilidade humana. (EPSTEIN, 1988c, p. 317, tradução nossa).

Epstein sugere que um cinema panteísta-perspectivista poderia desenvolver-se ao lado da emergente ciência da Física Quântica: "Um animismo está renascendo. Sabemos agora que estamos cercados de existências inumanas." (EPSTEIN, 1993, p. 190, tradução nossa). 0 cinematógrafo, como veículo de apropriação de perspectivas, está idealmente posicionado para interrogar o lugar do homem na narrativa terrestre. Essa mudança em direção a uma abordagem animista do cinema já havia aparecido no início do trabalho de Epstein. No entanto, foi após a Segunda Guerra Mundial e seu envolvimento de décadas com cenários naturais e fenômenos como tempestades, mares, ventos e nuvens, que as figuras humanas foram marcadamente descentralizadas. A região francesa da Bretanha forneceu material ilimitado para fraturar, deslocar e recontextualizar a realidade humana.

Essa mudança de perspectiva é evidente em Morv'ran (La Mer des Corbeaux), de 1931. Filmado na ilha de Sein, ao sul de Quessant, o curta conjuga imagens visualmente rimadas de tempestades, de ventanias, de um oceano furioso e de dois cemitérios dedicados, conta-nos o filme, aos pescadores que morreram no mar - com intertítulos poéticos, recheados de curiosas aliterações e jogos de palavras, que ressaltam insistentemente um descolamento do não humano da narrativa. "O mar fala", diz-nos uma das cartelas, como se acusasse uma certa transferência de subjetividade perpetrada pela câmera, da figura humana para a natureza. As formas ameaçadoras e deformadas que se afinam na tela parecem desumanas e evocam a forma como o cinema deforma e reforma tanto o corpo humano como a nossa visão natural. Morv'ran nos lembra a todo o momento que o cinema não é apenas um artifício ou uma máquina, mas uma maneira diferente de perceber o real que é, como sintetiza Wall Romana, “[...] tão antinatural quanto todos os artefatos humanos e tão natural quanto todos os fenômenos não humanos." (WALLROMANA, 2016, p. 121, tradução nossa).

Em Le tempestaire (1947), um segundo esforço em uma estrutura narrativa similar a Morv'ran, Epstein experimenta diversas variações de velocidade, explorando ideias a 
respeito do tempo no cinema como um conjunto de temporalidades simultâneas, fazendo com que o vento, o mar, a costa e os humanos se informem e interajam entre si, concedendo variadas perspectivas uns aos outros. Essas entidades são continuamente filmadas em câmera lenta, com uma manipulação igualmente singular do som. Epstein busca uma forma de trabalhar os aspectos figurativos do cinema. A maior parte do tempo de tela é completamente desprovida de presença humana, sendo os seres humanos, na maior parte do tempo, nada mais do que figuras contra um fundo furioso da Bretanha. O que vemos é algo entre o sólido e o líquido, o oceano vivo em movimentos viscosos, o cinema não como reprodução do movimento, mas como um novo movimento, criado através de variações da matéria audiovisual da imagem. James Schneider sintetiza bem a questão: "O filme é uma mise-en-scène notável do status perigoso da humanidade na Terra. Os seres humanos são transformados em objetos imóveis cercados por um mar furioso." (SCHNEIDER, 2012, p. 203, tradução nossa).

Le tempestaire é uma curiosa espécie de filme-manifesto do projeto epsteiniano de convergência cinematográfica de perspectivas humanas e não humanas. Neste sentido, o som funciona como um veículo fundamental. Le tempestaire foi a única oportunidade de Epstein de realmente experimentar o acesso a perspectivas por meio do "ouvido mecânico", abrindo todo um campo de possibilidades em relação à expressão da própria voz dessas entidades, independentemente da perspectiva humana. Em Le tempestaire, o som do oceano se desenrola em câmera lenta, para trás e para frente, com frequências e texturas desenhadas a partir do caos da tempestade de inverno. Epstein previu que o cinema um dia usaria um "perspectivismo sonoro", através do qual poderíamos não apenas ver objetos se expressando, mas penetrá-los por meio dos ouvidos.

\section{Alfred North Whitehead}

Epstein não conhece nenhuma divisão primordial, mas uma continuidade conflituosa. Le tempestaire é o fundador de sua própria realidade. Requer de nós um pensamento que não recue diante daquela experiência incerta e ambivalente que nos conecta estética, emocional e sensorialmente com o mundo. É aí que Alfred North Whitehead se torna um grande interlocutor. Ele tem um lugar importante na genealogia do que chamamos de realismo especulativo. Para Whitehead, o homem não é a medida de todas 
as coisas. Ele é um dos poucos pensadores do século XX que se atreveu a aventurar-se para além da esfera humana e colocar todas as entidades no mesmo patamar. Como o próprio Whitehead explica, nenhum privilégio ontológico especial pode distinguir Deus do "[...] sopro mais trivial da existência no distante espaço vazio [...]", e apesar de todas as "[...] gradações de importância e diversidade de função [...], todos estão no mesmo nível." (WHITEHEAD, 1978, p. 18, tradução nossa). E o que vale para Deus também pode ser dito sobre a subjetividade humana. 0 que ele prevê, portanto, é um mundo em que todas as coisas percebem umas as outras, em vez de apenas serem percebidas por nós.

O objetivo fundamental da filosofia de Whitehead é sempre o de superar o que ele mesmo chamou de "bifurcação da natureza", ou divisão absoluta entre "[...] a natureza apreendida na consciência e a natureza que é causa da consciência." (WHITEHEAD, 1994, p. 30-31). De um lado, há a aparência fenomênica do mundo para nós: "[...] o verde das árvores, o canto dos pássaros, o calor do sol, a dureza das cadeiras, e a sensação do veludo." (WHITEHEAD, 1994, p. 31). Do outro, há a realidade física oculta: “[...] o sistema de conjectura de moléculas e elétrons que tanto afeta a mente a produzir a consciência da aparente natureza." (WHITEHEAD, 1994, p. 31). O pensamento moderno é amplamente fundado sobre essa bifurcação (qualidades primárias e secundárias, noumena e phenomena, "a imagem manifesta" e "a imagem científica" etc.). Whitehead deseja superá-la em absoluto.

Não podemos empreender uma seleção rigorosa. Para nós, o fulgor avermelhado do poente deve ser parte tão integrante da natureza quanto o são as moléculas e as ondas elétricas por intermédio das quais os homens da ciência explicariam o fenômeno. Cabe à filosofia natural analisar como esses diferentes elementos da natureza se interligam. Ao fazer essa exigência, julgo-me adotando nossa atitude instintiva imediata para com o conhecimento perceptual, que somente é abandonado sob influência da teoria. (WHITEHEAD, 1994, p. 37).

O desejo de Whitehead de acabar com a bifurcação da natureza o fez mergulhar em um longo processo de especulação metafísica. No final, em obras como Process and reality e Adventures of ideas, ele delineia uma visão de âmbito cosmológico. Para Whitehead, o ser de uma coisa é constituído por seu devir. Na verdade, se quisermos ser rigorosos, não há coisas. 0 mundo é feito de processos, e cada coisa deve primeiro tornar-se o que é. Nada é dado 
previamente. Noções como "tornar-se" e "criatividade" são bastante genéricas na obra de Whitehead. Elas não se relacionam com seres humanos em particular. Eles podem referir-se a todos os acontecimentos no cosmos. Existem, naturalmente, diferenças de grau. Em Process and reality, Whitehead nos observa pelo menos duas vezes que o ser humano apresenta uma originalidade maior do que a de uma pedra. No entanto, essas diferenças de grau nunca são convertidas em diferenças de gênero. Todas as coisas são ativas e transformadoras. Desta forma, Whitehead mina o antropocentrismo inveterado da filosofia ocidental e engloba ambos os lados da bifurcação da natureza. Eu não sou um sujeito diante de um mundo que está fora de mim, porque sujeito e objeto “[...] são eles próprios processos de tornar-se, e todas as coisas reais são igualmente objetos [e] sujeitos." (WHITEHEAD, 1978, p. 56-57, tradução nossa).

\section{Antifilosofia}

A investigação de Epstein sobre as possibilidades do cinema também é a de uma nova maneira de ver o mundo e interagir com ele, baseada na extensão de nossos sentidos em novos domínios de sensibilidade. Epstein desenvolve essa ideia em sua obra mais visionária, L'intelligence d'une machine, publicada em 1946, na qual o cineasta promove a noção de que o cinema alimentaria uma intencionalidade autônoma que revolucionaria nossa visão do cosmos. É através do cinema e do que ele pode alcançar que Epstein chega à noção de "antifilosofia":

Sabemos que o cinematógrafo inscreve seu próprio caráter dentro de suas representações do universo, com tal originalidade que faz com que essa representação não seja simplesmente um registro ou cópia das concepções de sua mentalidade orgânica, mas verdadeiramente um sistema diferentemente individualizado, parcialmente independente, e compreendendo a semente do desenvolvimento de uma filosofia que se distancia de opiniões comuns a ponto de ser chamada de antifilosofia. (EPSTEIN, 1946, p. 124, tradução nossa).

Epstein continua descrevendo essa antifilosofia como sendo nascida da inteligência humana de uma maneira indireta, mas como um órgão autossustentável, um cérebro-robô, metade humano, metade máquina: 
Uma filosofia que com certeza não é completamente produzida por acaso, nem completamente desconhecida das leis da inteligência humana da qual ela é indiretamente nascida, mas uma filosofia de um cérebro-robô que não foi intencionalmente e estritamente regulada para realizar uma obra idêntica àquela do órgão vivo. (EPSTEIN, 1946, p. 187, tradução nossa).

Esse cérebro-robô, com seus “[...] dois sentidos fotoelétricos e sua memória de registro fotoquímica, constrói representações, ou seja, um pensamento no qual reconhecemos os principais quadros da razão." (EPSTEIN, 1946, p. 124, tradução nossa). A máquina cinematográfica possui razão e, nessa medida, assemelha-se à mente humana, embora funcione de maneira diferente. Ela não está limitada, de acordo com as palavras de Epstein, à "imitação servil da ideação humana” (EPSTEIN, 1946, p. 124, tradução nossa). Muito pelo contrário, e é isto o que a diferencia de outras máquinas: o cinematógrafo é uma máquina de intencionalidade autônoma que produz sua própria visão da realidade, desfazendo falsas dicotomias entre continuidade e descontinuidade, qualidade e quantidade, sugerindo noções diversas de espacialidade, tempo e causalidade. É, portanto, capaz de criar sua própria filosofia, sua antifilosofia de acordo com as palavras de Epstein.

A noção vizinha de lyrosophy, interessada em colocar no mesmo plano a razão e o sensível, duas noções que a filosofia ocidental teima desde Platão a descrever como dicotômicas, lança uma luz curiosa sobre essa dupla natureza - mecânica e humana - da antifilosofia. Em miúdos, a lyrosophy emerge da dupla natureza da inteligência humana, sensível e racional. Seu nascimento anuncia, portanto, um modo de inteligência totalmente novo e moderno que poderia ir além da ciência. 0 sensível e a razão deixam de ser encarados como antagônicos e se tornam um em uma estética lyrosophical. Essa estética ainda precisa ser descoberta e desenvolvida. Ela pertence ao futuro. É a tarefa que Epstein persegue em seus vários trabalhos, como se estivesse atrás de uma pedra filosofal:

Como a pedra filosofal, o cinematógrafo tem o poder de fazer transformações universais. Mas esse segredo é extraordinariamente simples: toda essa magia é reduzida à capacidade de variar a dimensão e a orientação temporais. A verdadeira glória, a realização mais surpreendente e talvez perigosa dos irmãos Lumière, não é abrir o caminho para a criação de uma 'sétima arte' - que, aliás, parece estar abandonando seu próprio caminho e contentando-se em ser um substituto do teatro -, mas ter criado a feitiçaria - [...] - que liberta nossa visão de mundo da escravização do único ritmo externo, solar, terrestre. (EPSTEIN, 1946, p. 163-164, tradução nossa). 


\section{Considerações finais}

Epstein acolhe uma arte que restitui à dualidade da vida e das ficções, da arte e da ciência, do sensível e do inteligível, a sua unidade original. O cinema dá origem a uma forma sensual de conhecimento perceptivo. O cinema é um paradoxo. Como a noção de antifilosofia sugere, não há para Epstein nenhuma verdade a ser encontrada, mas apenas perspectivas sobre a realidade. E, nesse sentido, a teoria do cinema é então parte de uma tentativa maior de refutar o ceticismo e de repensar e redefinir a visão e o conhecimento fora do quadro cartesiano da mente e do corpo.

Assim, em absoluta afinidade a Whitehead e aos realistas especulativos, Epstein nos faz experimentar nossos seres finitos e sentidos físicos na presença de um universo cujas possibilidades são infinitas. Seu cinema e teoria nos interpelam sobre essas possibilidades ainda não mapeadas e especulações inexploradas. Pensar o cinema com a ajuda do realismo especulativo, de Whitehead e de Epstein significa aceitar uma aventura da qual nenhuma das palavras que nos servem como nossos pontos de referência deve emergir intocada. Eles nos convidam a repensar as imagens em movimento não como epifenômenos culturais ou mecânicos, mas como uma primeira e fundamental filosofia, o nosso pensamento sobre o cinema sendo revertido em nome do pensamento cinematográfico em ato e para além de nós.

\section{Referências}

DELLUC, Louis. Écrits cinématographiques, Tome I: le cinéma et les cinéastes. Paris: Cinémathèque française; Paris: Cahiers du cinéma, 1985.

EPSTEIN, Jean. L'intelligence d'une machine. Paris: Jacques Melot, 1946.

EPSTEIN, Jean. Le cinématographe vu de l'Etna. In: Écrits sur le cinéma, Tome I, 19271947. Paris: Cinéma Club/Seghers, 1974.

EPSTEIN, Jean. Bonjour cinema and other writings. Afterimage, London, n. 10, p. 9-38, 1981.

EPSTEIN, Jean. Magnification. In: ABEL, Richard (ed.). French Film Theory and Criticism, 1907-1939: volume 1, 1907-1929. New Jersey: Princeton University Press, 1988a. 
EPSTEIN, Jean. The Senses 1. In: ABEL, Richard (ed.). French Film Theory and Criticism, 1907-1939: volume 1, 1907-1929. New Jersey: Princeton University Press, 1988b.

EPSTEIN, Jean. On Certain Characteristics of Photogenie. In: ABEL, Richard (ed.). French Film Theory and Criticism, 1907-1939: Volume 1, 1907-1929. New Jersey: Princeton University Press, 1988c.

EPSTEIN, Jean. Photogénie and the Imponderable. In: ABEL, Richard (ed.). French Film Theory and Criticism, 1907-1939: Volume 2, 1929-1939. New Jersey, Princeton University Press, 1993.

KELLER, Sarah; PAUL, Jason. (ed.). Jean Epstein: critical essays and new translations. Amsterdam: Amsterdam University Press, 2012.

MEILLASSOUX, Quentin. After Finitude: an essay on the necessity of contingency. London: Continuum Books, 2008.

RANCIÈRE, Jacques. A fábula cinematográfica. Campinas: Papirus, 2013.

SCHNEIDER, James. Cinema seen from the seas: Epstein and the Oceanic. In: KELLER, Sarah; PAUL, Jason. (ed.). Jean Epstein: critical essays and new translations. Amsterdam: Amsterdam University Press, 2012.

WALL-ROMANA, Christophe. Jean Epstein: corporeal cinema and Film Philosophy. Manchester: Manchester University Press, 2016.

WALL-ROMANA, Christophe. From Lyrosophy to Antiphilosophy: the thought of cinema in Jean Epstein. In: HERZOGENRATH, Bernd (ed.). Film as Philosophy. Minneapolis: University of Minnesota Press, 2017.

WHITEHEAD, Alfred North. 0 conceito de natureza. São Paulo: Martins Fontes, 1994. WHITEHEAD, Alfred North. Process and reality. New York: Free Press, 1978.

\section{Antiphilosophy: Jean Epstein and speculative realism}

\footnotetext{
Abstract

This article aims to propose a dialogue between Jean Epstein's movies and theory and speculative realism. The interaction of subjective and objective forces in cinema is a compelling field of investigation for a speculative realist, and the epsteinian conviction that cinema opens us to new domains of world knowledge is absolutely in tune with that philosophical
} 
movement. Throughout this dialogue, we struggle to outline a different way of thinking about cinema: an "antiphilosophy".

\section{Keywords}

Jean Epstein. Speculative realism. Antiphilosophy. Theory of filmmakers. A. N. Whitehead.

Recebido em 15/05/2019

Aceito em 01/07/2019 